\title{
EL VIDEOCLIP Y LA COMUNICACIÓN SOCIO-POLÍTICA: EL MENSAJE REIVINDICATIVO EN EL VÍDEO MUSICAL
}

Jennifer Rodríguez-López ${ }^{1}$ : Universidad de Huelva. España.

jennifer.rodriguez@dedu.uhu.es

Ana Sedeño-Valdellós: Universidad de Málaga. España.

valdellos@uma.es

\section{RESUMEN}

El vídeo musical como producto audiovisual difundido a través de los medios de comunicación masivos e internet supone una herramienta útil como transmisor de mensajes con un trasfondo social, político y cultural. El presente trabajo estudia, mediante una metodología crítico-estilística basada en el análisis y la descripción de los aspectos reivindicativos, diversos ejemplos de videoclips en los que se plantea un mensaje de denuncia social sobre varias temáticas como son los conflictos bélicos y políticos, los movimientos de igualdad de género y aquellos de liberación homosexual. Tras los distintos análisis, se concluye el poder del vídeo musical para la difusión de estos mensajes y su aportación a la lucha pro-derechos dentro de la iconosfera contemporánea, no solo como formato audiovisual hipermedia sino también como un mecanismo que a través de la seducción y el espectáculo facilita la comunicación de los mensajes sociales de una forma amena, velada y casi invisible.

\section{PALABRAS CLAVE}

Vídeo musical - Reivindicación - Medios de comunicación de masas - Mujer Conflicto - Política - Publicidad

\section{VIDEO CLIP AND SOCIO-POLITICAL COMMUNICATION: THE VINDICATING MESSAGE IN THE MUSIC VIDEO}

\begin{abstract}
The music video as an audiovisual product broadcasted through mass media and it is a useful tool in order to transmit social, cultural and political messages. Through a criticism-stylistics-based methodology grounded in the analysis and description of vindicating aspects, the present paper studies several examples of video clips which convey a message of social denounce about multiple matters such as warfare,

\footnotetext{
${ }^{1}$ Jennifer Rodríguez-López: Es doctora en Educación y Comunicación Audiovisual, Máster en por la Universidad de Huelva (España). Es miembro del Grupo de Investigación Ágora y Miembro del Comité de Revisores Científicos Internacionales de la Revista «Comunicar».

jennifer.rodriguez@dedu.uhu.es
} 
political, gender and sexual identity movements. This piece of research tries to confirm the power of the music video clip in the dissemination of this kind of messages and its contribution to the pro-rights struggles, not only as an audiovisual, hypermedia format but also as a mechanism that facilitates communication of profound social messages through seduction and spectacle in an entertaining, veiled and almost invisible way.

\section{KEY WORDS}

Music Video - Vindication - Mass Media - Woman - Conflict - Politics - Advertising

\section{O VIDEOCLIPE E A COMUNICAÇÃO SÓCIO-POLÍTICA: A MENSAGEM REIVINDICATIVA NO VÍDEO MUSICAL}

\section{RESUMO}

O vídeo musical como produto áudio visual difundido através dos meios de comunicação massivos e internet supõem uma ferramenta útil como transmissor de mensagens com um fundo social político e cultural. O presente trabalho estuda mediante uma metodologia critica-estilistica baseada na analises e descrição dos aspectos reivindicativos, diversos exemplos de videoclipes em que se propõem uma mensagem de denúncia social sobre várias temáticas como são os conflitos bélicos e políticos, os movimentos de igualdade de gêneros e de liberação homossexual. Depois das distintas analises, se conclui o poder do vídeo musical para a difusão dessas mensagens e seu aporte a luta pró- direitos dentro da iconosfera contemporânea, não somente como formato audiovisual hipermídia, se não também, como um mecanismo que através da sedução e o espetáculo facilita a comunicação das mensagens sociais de uma forma amena, velada e quase invisível.

\section{PALAVRAS CHAVE}

Vídeo musical - Reivindicação - Meio de Comunicação de Massas - Mulher Conflito - Política - Publicidade

\section{Cómo citar el artículo}

Rodríguez López, J.; Sedeño Valdellos, A. (2017) El videoclip y la comunicación socio-política: el mensaje reivindicativo en el vídeo musical [Video clip and sociopolitical communication: The vindicating message in the music video] Vivat Academia. Revista de Comunicación, 138, 1-15 doi: http://dx.doi.org/10.15178/va.2017.138.1-15 Recuperado de http://vivatacademia.net/index.php/vivat/article/view/985

\section{INTRODUCCIÓN}

La música popular es una modalidad comunicativa y cultural, con todo un universo de implicación emocional que permite, a su vez, ciertos niveles de control ideológico y social. Si se piensa en los instrumentos con los que las empresas discográficas intentan vehicular esa influencia y conseguir visibilidad y beneficio económico, 
pueden encontrarse formatos como el videoclip musical, punto de encuentro entre música, medios audiovisuales e industria discográfica. Su origen ligado a prácticas publicitarias y promocionales permite subrayar su naturaleza de «maquinaria ideológica» (Vernallis, 1998, p. 153) y su capacidad de construir socialmente a los individuos.

Aunque escasa, existe alguna bibliografía asociada al análisis del videoclip como agente de influencia social. Durante los años ochenta, primaron los análisis de contenido del videoclip en términos de estudio de las temáticas más empleadas. Baxter y otros (1985) encontraron imágenes de sexo, baile y violencia en al menos la mitad de sus 62 casos de estudio. Sherman y Dominick (1986) analizaron 166 vídeos, donde constataron la presencia hegemónica de violencia y sexo. En los noventa, Markman (1999), continuó esta vertiente con análisis de contenido y de clima visual, bajo criterios de valores y estilos de vida, actitudes vitales, relación entre géneros, actividades practicadas y carácter de las instituciones. Sus conclusiones describen unos mensajes con disposición hacia el optimismo (climas visuales que tienden a una visión idealista de las relaciones interpersonales), la alegría y la felicidad, casi en igual medida con una tendencia hacia el pesimismo y el nihilismo, mezclado con contenidos hedonistas e individualistas, es decir, un modelo de valores muy próximo a lo postmoderno.

Otras investigaciones (Seidman, 1992; Sommers-Flanagan, Sommers-Flanagan, y Davis, 1993; Vincent, 1989; Tapper, Thorson y Black, 1994) han analizado el papel de la mujer en los videoclips, demostrando su tendencia al estereotipo. Si se analizan las representaciones culturales femeninas posteriores a la década de los noventa, pueden constatarse algunas destilaciones de posicionamientos postfeministas. En este sentido, se les asignan comportamientos agresivos (Inness, 2004; Gill y Scharff, 2011) y se les describe como sujetos sexuales. Como apuntan algunas investigaciones, con frecuencia los personajes femeninos de las series, los vídeos musicales, las películas y demás mensajes televisivos se desarrollan en ambientes que tienden a describir actitudes contradictorias, sin que esto signifique un debilitamiento de las bases del patriarcado y dominación de la mujer. Por un lado, son sujetos deseables, que siguen dependientes de una mirada masculina que las desea y las fetichiza; por otro, estas mujeres utilizan este poder como fuente de empoderamiento, combinando nuevos roles como los de chica guerrera y los de fashion divas (Tortajada y Araüna, 2014).

Vernallis (1998) es otro referente en este caso, ya que en su trabajo trata de realizar un análisis sobre la construcción del cuerpo y la representación de la imagen de los cantantes y músicos en el videoclip. La autora asume y demuestra que se pueden generalizar formas de elaborar la representación de categorías como sexualidad, género y raza. Más recientemente, Railton y Watson (2011) abordan el vídeo musical en términos políticos mediante algunas categorías provenientes del postfeminismo, los estudios sobre la identidad grupal, racial y subcultural y la nueva subjetividad masculina. 


\section{OBJETIVOS}

Los objetivos de esta investigación se encuentran relacionados con el papel del vídeo musical como transmisor de mensajes más allá de su motivación como producto publicitario de la industria discográfica. Por ello, entre los objetivos planteados se encuentran los siguientes:

1. Visualizar el videoclip como un instrumento ideológico cargado de mensajes sociopolíticos

2. Analizar el vídeo musical como vehículo transmisor de dichos mensajes

3. Reconocer el poder del clip como motor de reivindicación social

4. Estudiar el contenido de los mensajes de los vídeos musicales reivindicativos y de los elementos musicovisuales utilizados

5. Aproximarse al videoclip de contenido sociopolítico desde una perspectiva crítico-estilística

\section{METODOLOGÍA}

El concepto de investigación queda definido por McMillan y Schumacher (2005, p. 11) como «el proceso sistemático de recogida y de análisis lógico de información (datos) con un fin concreto». Por ello, la metodología de esta investigación ha sido seleccionada de acuerdo con la naturaleza de esta, por lo que es de tipo descriptivo, basada en el análisis y la descripción de las distintas categorías y dimensiones significativas del objeto de estudio. Los datos obtenidos a través de la observación directa sobre el texto audiovisual son tratados mediante procedimientos analíticos a partir de dos tareas: el manejo de los datos y su interpretación (Gibbs, 2012, p. 21). El método utilizado se define de este modo mediante la observación objetiva y la descripción de los datos analizados para su posterior interpretación. Se trata de lo que Taylor y Bogdan (1987, p. 17) definen como «observación descriptiva», de la que se parte para su posterior análisis mediante la aplicación de una parrilla metodológica. Por ello, a través de la descripción y la comprensión del objeto de estudio se tratará de elaborar un modelo conceptual explicativo, con la pretensión de alcanzar un mayor conocimiento de la realidad estudiada.

En este trabajo se seguirán distintas líneas de investigación relacionadas con el vídeo musical como mecanismo de reivindicación social entre las que destacan las siguientes:

1) El vídeo musical, debido a su carácter masivo, se convierte en un potente vehículo social capaz de difundir mensajes relacionados con los problemas actuales

2) Gracias a la naturaleza experimental, seductora y lúdica del videoclip dichos mensajes son transmitidos de forma sutil en la iconosfera contemporánea

3) El vídeo musical hace uso de las reivindicaciones sociales como recurso expresivo y provocador, de forma paralela al discurso de lucha social

Los fundamentos que justifican esta investigación se basan en la trascendencia y novedad del tema, ya que se aprecia un interés por el vídeo musical como objeto de estudio académico. Se trata de una temática relacionada con la didáctica de los 
medios de comunicación y la enseñanza en el análisis de los mismos. Se observa una carencia en este ámbito de estudio, en relación a investigaciones basadas en el análisis de los mensajes reivindicativos en el vídeo musical.

La muestra analizada se define por ser de tipo no probabilística, ya que se hacen uso de criterios reflexivos y razonados que justifican la elección de la misma. Así, los videoclips analizados abarcan un amplio período temporal, ya que se incluyen clips desde los inicios del formato en la década de los ochenta hasta la actualidad. Se trata de vídeos musicales de fama y reconocimiento internacional, realizados por directores de prestigio y difundidos por canales mundiales tanto de plataformas televisivas como en internet. De este modo, la muestra se compone de distintos vídeos musicales agrupados en torno a cuatro temáticas principales en relación con los movimientos sociales predominantes en la actualidad: la igualdad de género, la liberación gay, los movimientos solidarios y los conflictos bélicos y de tipo político.

\section{DISCUSIÓN. LA DIFUSIÓN DE LOS MENSAJES SOCIALES Y POLÍTICOS A TRAVÉS DEL VIDEOCLIP}

\subsection{La imagen de la mujer y la igualdad de género en el videoclip}

La emancipación femenina se inició como movimiento ya en la Revolución Francesa y supuso la reivindicación de la igualdad entre hombres y mujeres en materia política, legal, profesional, social, familiar y personal. La celebración tras conseguir el sufragio femenino dio paso al feminismo y al postfeminismo actual que trata de crear una imagen de superación de la mujer. Para Tortajada y Araüna (2014: 26), este fenómeno ideológico se caracteriza por:

La representación de las mujeres como sujetos sexuales (que desean y que, sobretodo, quieren ser deseadas), por la sexualización de la cultura y por un énfasis en la diferencia natural entre sexos, en el individualismo y en el consumismo. Incorpora parcialmente las reivindicaciones feministas, pero lo hace redefiniendo el concepto de empoderamiento y la conexión entre consumismo y feminismo de tal modo que política y activismo quedan desplazados por conceptos menos combativos como el 'estilo de vida' o la 'actitud'.

Como apuntan las autoras, observándose en los roles asumidos en el vídeo musical, las mujeres aparecen erotizadas y con una actitud de superación, de forma opuesta al papel desempeñado en épocas anteriores en las que la sumisión y la pasividad eran los rasgos femeninos predominantes.

Por ello, el videoclip se convierte en un transmisor de los estereotipos de género. Colás y Villaciervos (2007, p. 37) afirman que los estereotipos son «una representación cultural, que contiene ideas, prejuicios, valores, interpretaciones, normas, deberes, mandatos y prohibiciones sobre la vida de las mujeres y de los hombres». El vídeo musical, como formato publicitario inmerso en los medios de comunicación masivos, hace uso de los estereotipos por su comodidad y su fácil identificación, por lo que favorece el arraigo de estos en la sociedad. Por otra parte, García-Ruíz y otros (2014-1015, p. 579) sostienen que «los medios de comunicación ofrecen representaciones de la realidad social, que responden a intereses o 
prioridades sobre los temas y problemas a tratar y cuya influencia condiciona nuestra percepción del entorno», suponiendo así un vehículo para las ideas reivindicativas. Así, el videoclip facilita la presentación de una imagen de la mujer cercana a la superación, la fuerza y el poder, definiendo un nuevo rol femenino.

En los vídeos musicales actuales se observa esta dicotomía y se promueve una representación femenina próxima al erotismo casi pornográfico, a la agresividad hacia los personajes masculinos y a la provocación, con el fin de reivindicar su papel en la sociedad. Estos rasgos se ejemplifican en el clip de 2002 dirigido por David Lachapelle para el tema "Dirrty" de Christina Aguilera en el que esta aparecía semidesnuda y con una actitud de dominación a través de su sexualidad. Este vídeo fue censurado por su contenido erótico, utilizado para presentar una imagen de la mujer más poderosa y reivindicativa.

La denuncia de la situación de la mujer en la sociedad se realiza en los vídeos "Stupid Girls" de Pink de 2005 y "Tell me Where it Hurts" del grupo Garbage de 2007. El primero de ellos, dirigido por Dave Meyers y con una duración de tres minutos y treinta y dos segundos, pretende la concienciación de las mujeres sobre su propio cuerpo, denunciando los modelos corporales presentes en los medios de comunicación y promoviendo la aceptación de estéticas más realistas. El clip denuncia la implantación de ideas erróneas como la superficialidad, realizando una parodia de la cirugía estética, los trastornos alimenticios e incluso el rol de la mujer en los vídeos musicales protagonizados por hombres.

En "Tell me Where it Hurts", dirigido por Sophie Muller, con una duración de cuatro minutos y diez segundos, se realiza una denuncia del maltrato de género y la dominación sexual por parte del hombre. La cantante muestra los hematomas fruto de los golpes mientras interpreta la canción. Finalmente, tras vengarse de su agresor, muestra una actitud triunfal y de dominación.

Dicha actitud triunfal se manifiesta de otro modo en el clip "Run the World (Girls)" de Beyoncé de 2011, dirigido por Francis Lawrence. Con una duración de cuatro minutos y cincuenta y seis segundos, presenta una batalla campal entre hombres y mujeres. La cantante lidera al grupo femenino con una actitud agresiva, fuerte y potente. A través del título y la letra de la canción se subraya su carácter reivindicativo apoyado en las imágenes, incidiendo en el nuevo papel de la mujer en el mundo. En esta misma línea, se sitúa el vídeo de Lily Allen "Hard Out Here" de 2013, dirigido por Christopher Sweeny. En él se invierten los estereotipos asociados con la mujer y se parodian los roles tradicionales atribuidos a hombres y mujeres desde un tono irónico, denunciando los abusos de las industrias discográficas hacia estas.

Actualmente destacan los vídeos musicales de Meghan Trainor, sirviendo como ejemplos "All About the Bass" (2015) y "Dear Future Husband" (2015). Ambos, dirigidos por Fátima Robinson y de estética similar, presentan nuevos cánones de belleza alejados de la extrema delgadez y animan a la aceptación de los diferentes modelos estéticos. Al mismo tiempo tratan de transmitir un mensaje de autenticidad y ruptura de los roles estereotipados y tradicionales, promoviendo una actitud más proactiva de la mujer en todas las facetas de la sociedad. 


\subsection{El movimiento de liberación gay y la provocación clip}

Los movimientos de liberación homosexual comenzaron en Estados Unidos a finales de la década de los sesenta. En 1969 tuvo lugar en la ciudad de Nueva York una marcha por el orgullo gay desde el barrio de Greenwich Village, como respuesta a unos disturbios producidos contra el colectivo homosexual en el club Stonewall. Este hecho inspiró los actos pacíficos que desembocaron en la recuperación de los derechos de dicho colectivo así como en la creación de organizaciones homófilas como el Frente de Liberación Gay. Sus reivindicaciones se difundieron por Europa y el resto del mundo, consiguiendo derechos como el matrimonio y la adopción. Así, sus principales objetivos en relación a la situación de homosexuales, lesbianas, bisexuales y transexuales se resumían en la abolición de las leyes que penalizaban la homosexualidad, la concienciación de los derechos de estas personas para conseguir la igualdad con los heterosexuales y la erradicación de los prejuicios y otras actitudes negativas (Noir, 2010: 130). Surgieron numerosos tabúes pero al mismo tiempo distintas reivindicaciones en torno a la homosexualidad y al papel tradicional de hombres y mujeres en relación a la maternidad, las relaciones sexuales, el ámbito doméstico y familiar, la anticoncepción o las enfermedades de transmisión sexual como el virus de inmunodeficiencia humana (VIH), conocido en 1980 como el cáncer gay.

El papel reivindicativo del vídeo musical se observa desde los inicios del formato. En 1984 el clip "Relax" de Frankies Goes to Hollywood, dirigido por Bernard Rose, fue censurado y prohibido por la BBC y la MTV ya que sus acciones eran presentadas en un bar gay en el que se realizaban prácticas sexuales de tipo sadomasoquista. Del mismo director y año, "Smalltown Boy" (1984) del grupo británico Bronski Beat se convirtió en un himno gay por el contenido de su letra en la que aparecen estrofas como la siguiente: «Pushed around and kicked around/Always a lonely boy/You were the one/That they'd talk about around town». En este clip, con una duración de 4 minutos y 57 segundos, se presenta a un joven homosexual que vive en un pequeño pueblo con sus padres y que sufre una agresión homófoba. Tras hablar con un chico al que incomoda, recibe una paliza por parte de este y de sus amigos. Ante el rechazo de su familia y de la sociedad conservadora y tradicional en la que vive, se ve obligado a marcharse a la ciudad para sentirse aceptado. También en la década de los ochenta y relacionados con la temática gay aparecen los vídeos "I Want to Break Free" (1984) de Queen y "Domino Dancing" (1988) de Pet Shop Boys.

En los años noventa existen numerosos clip que utilizan el carácter masivo de este formato como un transmisor del mensaje social. Sirve como ejemplo "Outside" (1998) de George Michael. Este clip, dirigido por Vaughan Arnell y con una duración de 5 minutos y 36 segundos, surge como respuesta tras el arresto del cantante por mantener relaciones sexuales con otro hombre en un baño público, lo que le obligó a confirmar su homosexualidad. En el videoclip se presentan numerosas escenas en las que parejas, tanto heterosexuales como homosexuales, practican sexo en lugares al aire libre, lo que supone una sátira de lo ocurrido. El título y la letra de la canción, cuyo estribillo dice «Let's go outside (let's go outside)/In the sunshine/I know you want to, but you can't say yes/Let's go outside/In the moonshine/Take me to the 
places that I love best», toman así un doble sentido ya que animan a practicar sexo en escenarios exteriores al mismo tiempo que inducen a la liberación homosexual.

Desde la llegada del nuevo milenio hasta la actualidad se han sucedido vídeos musicales que han utilizado de igual modo la sexualidad homosexual tanto como un acto de denuncia social así como un recurso provocativo. De este modo, "All the Things She Said" (2002) de t.AT.u., de 3 minutos y 49 segundos y dirigido por Ivan Shapovalov, muestra una escena en la que las dos jóvenes aparecen encerradas tras una reja mientras son observadas por una multitud al otro lado de la valla metálica. Las chicas se besan bajo la lluvia y la nieve luchando contra las miradas y las condiciones impuestas por el grupo de adultos. Finalmente, abandonan su cautiverio y parece que son ellos quienes estaban prisioneros de sus prejuicios. Pertenecen a este mismo período y temática "Androgyny" (2001) de Garbage, "I Kissed a Girl" (2008) de Katy Perry y "All American Boy" (2013) de Steve Grand.

Como ejemplos más actuales sobre la reivindicación del colectivo homosexual aparecen los clips "Same Love" (2012) de Macklemore \& Ryan Lewis feat Mary Lambert, y "Take Me To Church" (2015) de Hozier. El primero, dirigido por Ryan Lewis y Jon Jon Augustavo y con una duración de 7 minutos, narra la vida de un joven homosexual desde su nacimiento, mostrando las dificultades emocionales y el rechazo sufrido por este colectivo por instituciones como la iglesia y la sociedad en general. Debido a su contenido y a su participación en la campaña a favor del matrimonio entre personas del mismo sexo, recibió el premio al Mejor Vídeo con Mensaje Social de la MTV en 2013. Por su parte, "Take Me To Church", dirigido por Brendan Canty y Conal Thomson, presenta un amor homosexual perseguido de forma violenta por un grupo de jóvenes homófobos. La belleza de las imágenes en blanco y negro se contrapone a la dureza del mensaje, remarcado por el tono de la letra.

\subsection{Los Charity Singles: Entre el marketing y la denuncia social}

Como se ha defendido en este artículo, el vídeo musical se convirtió, casi desde sus inicios como formato audiovisual experimental, en un vehículo transmisor de mensajes sociales, culturales y políticos. Gracias a su valor publicitario y su poder de seducción, surge una modalidad solidaria denominada Charity Singles. Cuesta (2007: 20) afirma que:

A partir de la segunda mitad de los ochenta muchos artistas descubren el potencial del videoclip como medio de expresión reivindicativa en cuanto a cuestiones políticas y de género, pero también referida a otras libertades. Es decir: se toma la conciencia de que el videoclip puede ser un arma para algo, para vehicular un mensaje o un propósito, o para mover a la acción.

De esta forma surgen estas canciones solidarias, a medio camino entre las estrategias de marketing y la difusión de causas benéficas, definidas por la anterior autora (Cuesta, 2007: 20) como «la suma de esfuerzos de diversos intérpretes conocidos por el público cuya finalidad es recaudar fondos para una causa humanitaria o solidaria». Estos vídeos musicales se caracterizan por presentar a los artistas realizando la performance de la canción -en ocasiones en el propio estudio de grabación-, con 
intercalación en montaje de escenas de la causa para la que se pretende recaudar beneficios. Así, una de las primeras expresiones solidarias fue la actuación televisada del grupo Bee Gees con la canción "Too Much Heaven" en 1979 como contribución para la campaña Music for UNICEF Fond.

Pero sin duda el clip solidario con mayor difusión es “We Are the World" (1985), contra el hambre en Etiopía y en el que participaron numerosos artistas entre los que se encuentran Michael Jackson, Diana Ross, Stevie Wonder, Bob Dylan y Bruce Springsteen, bajo el nombre de USA for Africa. Se recaudaron más de 50 millones de dólares además de recibir distintos premios como al Vídeo del Año por la MTV. El videoclip tiene una duración de ocho minutos y mantiene la estructura anteriormente descrita para esta tipología clip. Lo primordial es mostrar el mayor número de artistas participantes, prescindiendo de otros elementos de la representación y la narración. Por ello, la puesta en escena y el concepto se caracterizan por la simplicidad y la concreción del mensaje solidario a través de los gestos de los artistas y la letra de la canción.

En 1990, surgió otra propuesta musicovisual solidaria a través de la organización Red Hot, dedicada a combatir el SIDA a través de la cultura Pop, y para la que se realizó Red Hot+Blue compuesto por un álbum en el que se realizaron versiones de canciones interpretadas por Cole Porter y en el que participaron artistas internacionales como Sinéad O'Connor, Debbie Harry, Iggy Pop, U2 y Annie Lennox, entre otros. De algunos temas se realizaron videoclips con la colaboración de prestigiosos directores como "In The Still of the Night" de The Neville Brothers y dirigido por Jonathan Demme y "It's All Right With Me" de Tom Waits y bajo la dirección de Jim Jarmusch. Destaca entre ellos "I've Got You Under My Skin" de Neneh Cherry con Jean-Baptiste Mondino como director. En este clip, la cantante rapea un alegato contra la desinformación sobre el virus del SIDA y promueve la concienciación sobre esta enfermedad. Las iniciativas de esta organización continúan en la actualidad con colaboraciones entre diversos artistas que apoyan la causa.

\subsection{La visión de los conflictos bélicos y políticos en el vídeo musical}

En relación con las reivindicaciones sociales y humanitarias, el vídeo musical se convierte en un potente transmisor, apoyado en la imágenes y en el efectismo de la banda sonora, de mensajes de denuncia política y de tipo pacifista. Penalva (2002: 402) afirma que «en las guerras contemporáneas las relaciones entre poder y medios mantienen algunos elementos que podemos llamar tradicionales (propaganda y control de los medios), pero también aparecen nuevos aspectos relacionados con el desarrollo de las comunicaciones y la globalización». Los conflictos actuales son retransmitidos en directo de forma globalizada y sus consecuencias afectan de manera mundial. Por ello, el vídeo musical se hace eco de esta problemática haciendo uso de reivindicaciones políticas en su aparato retórico y seductor, a menudo en consonancia con la letra de las canciones que denuncian dichas situaciones, promoviendo la conciencia colectiva.

En el clip "This is Radio Clash" de The Clash (1981) se muestran imágenes relacionadas con desigualdades sociales y conflictos bélicos presentadas a través de los medios de comunicación. Con una duración de cuatro minutos y siete segundos, 
aparecen escenas de manifestaciones pacifistas, francotiradores apostados en los edificios, cámaras de televisión y antenas que pretenden reflejar la mediación de las cadenas de televisión y radio en la información sobre los conflictos recibida por la sociedad.

Uno de los vídeos musicales con matiz belicoso de mayor difusión es "Another Brick in the Wall" de Pink Floyd, incluido en el largometraje musical The Wall de 1982. Este clip supone una crítica de las consecuencias de la Segunda Guerra Mundial y del gobierno nazi. Dirigido por Alan Parker, presenta los elementos propios de la guerra como la disciplina militar, la alienación y la destrucción material y humana. Supone una de las primeras denuncias de los resultados de la guerra en la sociedad mediante la combinación de la banda sonora y la banda icónica, creando una potente maquinaria efectista.

Por su parte, "Born in the U.S.A." (1984) de Bruce Springsteen está considerada por parte del público como un himno patriótico cuya letra y vídeo musical ensalzan las costumbres y virtudes de la sociedad norteamericana. Sin embargo, otra visión sugiere que se trata de una canción protesta de corte pacifista que pretende denunciar los abusos cometidos por el gobierno americano durante la Guerra de Vietnam, así como el maltrato a los veteranos de guerra y otras problemáticas sociales como los derechos de los trabajadores, el uso de las armas o el racismo. El clip, dirigido por John Sayles y con una duración de 4 minutos y 53 segundos, intercala imágenes de una actuación en directo del cantante con escenas cotidianas de Norteamérica tales como una bandera ondeando al viento, trabajadores a la salida de las fábricas así como soldados, armas y cementerios de las víctimas de la guerra. En la letra se hace alusión a las armas y al conflicto entre EE.UU. y Vietnam al hacer referencia a "the yellow men", "Khe Sang", "Viet Cong" y "Saigon" así como al departamento dedicado a los veteranos de guerra.

Posteriormente, en la década de los noventa, destaca el clip de Eurythmics "I Saved the World Today", dirigido en 1999 por David A. Stewart, y que supone una petición de paz. La letra de la canción, incluida en su álbum Peace, contiene un mensaje pacifista, denunciando sutilmente las consecuencias de la guerra, las pérdidas de soldados, el duelo de las familias, los estragos de los conflictos bélicos en la sociedad, al mismo tiempo que se aprecia un sentido irónico en el tono de la misma, visible también en las imágenes. En este vídeo musical, de 4 minutos y 47 segundos, se muestran dos escenas. En la primera de ellas aparece la banda, liderada por la cantante, con vestuario de tipo militar, ropa de camuflaje, chapas de identificación, e incluso el batería lleva una camiseta con la estrella anarquista. Tras el primer minuto y medio se muestra una enorme orquesta, dispuesta en una escalinata, compuesta por músicos uniformados como mandos militares. A continuación, algunas de las autoridades militares abandonan sus puestos para observar cómo los intérpretes de la canción firman un tratado de paz en el que se lee "Peace Ready". La tinta cae sobre el papel, creando una metáfora visual.

Con el mandato de George W. Bush y el conflicto de Irak en 2003 surgieron numerosos videoclips que denunciaban las consecuencias de la guerra y la actitud belicista del gobierno de Estados Unidos. Destaca "Shoot the Dog" de George Michael (2002), que muestra mediante la animación y de forma burlesca la ineptitud 
del expresidente de EE.UU. Bush, apareciendo también Tony Blair como su perrito faldero y Saddam Hussein junto a misiles como los personajes implicados en la guerra contra Irak tras el atentado a las Torres Gemelas en 2001. Este clip, de cinco minutos y veintisiete segundos de duración, trata de enviar un mensaje pacifista y antibelicista.

"American Life" de Madonna presenta tres versiones, todas dirigidas por Jonas Åkerlund, ya que el clip fue censurado por su contenido crítico contra el gobierno norteamericano. En la primera versión, de 4 minutos y 50 segundos, se presenta a la intérprete vestida como un alto mando del ejército. Las acciones se desarrollan en un desfile de moda en el que todos los personajes llevan uniformes del ejército estadounidense. Se intercalan imágenes de aviones militares, misiles y bombardeos, mutilados y heridos. También aparecen en el desfile niños iraquíes como principales víctimas de la guerra. Finalmente, Madonna lanza una granada que es recogida por el presidente Bush, asistente al desfile. En la versión censurada aparece la cantante vestida de la misma forma sobre un fondo de banderas de distintos países, concluyendo con la bandera americana. Sirven también como ejemplos de la reivindicación política contra el gobierno estadounidense los clips "American Idiot" (2004) y “Wake me up When September Ends" (2005) ambos de Green Day.

\section{CONCLUSIONES}

Desde los inicios del vídeo musical como formato, en la década de los ochenta, el principal medio para su difusión fue la televisión. Sin embargo, este panorama está cambiando. Selva (2012: 1) afirma que no puede identificarse a este formato con la televisión, «en la medida en que existen otros medios que han ido cobrando un protagonismo cada vez mayor en la difusión del videoclip», y Roncero-Palomar (2008: 281) sostiene que «el vídeo musical comienza a abandonar la plataforma que lo hizo popular, la televisión. En su lugar se sitúan los nuevos dispositivos electrónicos, capaces de reproducir contenidos multimedia». Así, en la actualidad, los espacios dedicados al videoclip en este medio pública son muy escasos o inexistentes, los canales temáticos han dejado de emitirlos veinticuatro horas y las plataformas web en internet los han sustituido, facilitando la difusión masiva del clip y sus mensajes socio-políticos. Existen varias webs dedicadas a los vídeos musicales, tales como YouTube, Google Video, MySpace, Metatube, Jukebox, Vimeo, BlipTv y Tu.tv, entre otras webs basadas en los UGC (User Generated Content o contenidos generados por el usuario). El desarrollo de la web 2.0 y la elección de contenidos por parte del usuario que esta permite, suponen una democratización de los contenidos y posibilita el consumo de mensajes que escapan de lo comercial.

De este modo, y gracias a esta naturaleza masiva, el vídeo musical se ha convertido en un potente transmisor de ideas políticas que tratan de concienciar a la sociedad en nuevos valores. Mediante la figura del cantante como modelo de conducta se favorece la implantación de conciencias basadas en el antibelicismo, el pacifismo, la igualdad sexual y de género así como la superación de las diferencias económicas y sociales. Como apunta Penalva (2002, p. 396), «en un mundo donde una gran parte de las relaciones sociales se desenvuelve en el universo mediático, bajo sus diversas 
formas tecnológicas y de contenidos (información, entretenimiento, conocimiento y formación) los medios adquieren una fenomenal influencia».

El aparato seductor del videoclip se erige como una efectista maquinaria capaz de articular nuevos modelos de pensamiento. La combinación de la música con las imágenes, así como la inclusión de novedosas técnicas lo convierten en una herramienta perfecta de reflexión, de transmisión de ideas, pero también de manipulación. Se evidencia un uso de la violencia y de la provocación como un mecanismo publicitario más, inmerso en un circuito de recursos que tratan de mantener y fijar la atención del espectador sobre el producto. Tal y como afirma Penalva (2002: 398), «el público demanda violencia y no sólo por su espectacularidad (...), sino también por la afición a la 'mirada morbosa' sobre las imágenes o relatos 'reales' que ofrecen los medios». Como se refirió en el apartado metodológico, se evidencia el uso que realiza el vídeo musical de las reivindicaciones sociales como recurso expresivo y provocador, de forma paralela al discurso de lucha social. De esta forma, la presencia de escenas violentas extraídas de la realidad de la guerra poseen en el videoclip una doble función: la denuncia y la atracción.

La tendencia actual en los medios de comunicación y de información es presentar los hechos de forma morbosa y provocadora, con el fin de aumentar la audiencia. Los telediarios presentan en horario infantil imágenes de desastres y conflictos bélicos sin pudor. Este testigo es recogido por el vídeo musical, tratando de explotar todos los recursos espectaculares que posee. Por ello, son numerosos los clips reivindicativos en los que se muestran directamente imágenes de las consecuencias de la guerra y de las carencias económicas en los países subdesarrollados, del maltrato de género o de los conflictos homófobos. Bryant y Zillmann (1996, p. 603) apuntan los motivos de esta atracción de los medios de comunicación hacia la violencia. Según estos autores «proporcionan al espectador satisfacción a su curiosidad morbosa, permiten celebrar su sensibilidad emocional al comprobar sus reacciones de rechazo e incitan a la comparación social de su situación con la de los sujetos que aparecen en los medios». En cuanto a las reivindicaciones sexuales y de género, estas se producen en el videoclip alejándose de los estereotipos asociados tanto a la mujer como al colectivo homosexual, al mismo tiempo que se crean nuevas imágenes que forjan lugares comunes. Es el caso de la nueva representación femenina que se observa en el clip y que presenta a una mujer fuerte, independiente y con una actitud dominante hacia los hombres. Sin embargo, esta imagen está comenzando a estereotiparse ya que, como indica Márquez (2014: 183), «el videoclip, pues, se presenta como otra tecnología de la visión que contribuye a reproducir las estructuras de un sistema patriarcal asentado desde hace años y que sigue alimentando estereotipos y modelos femeninos que limitan la capacidad de acción de las mujeres». Para el autor, las respuestas feministas y los mensajes más críticos se realizan desde el underground, es decir, lejos de los circuitos comerciales, ya que estos se encuentran más «con la igualdad de sexo y la no explotación de la mujer con fines comerciales y sexuales» (Márquez, 2014: 187).

Esta realidad deviene en la hipersexualización que caracteriza a los mensajes visuales entre los que se incluye el vídeo musical. Martínez-Noriega (2014: 63) afirma sobre este fenómeno que «existe una avidez excesiva de la sexualidad y lo sexual, que 
pudiera parecer en ocasiones una especie de obsesión». La autora continúa subrayando el bombardeo de imágenes de contenido sexual que sufre la sociedad actualmente a través de los medios y acentúa el papel de la publicidad en la difusión de dicha fascinación.

Como conclusión se reafirma el papel determinante del vídeo musical como mecanismo generador de modelos de comportamiento y roles sexuales así como de diferencias de género, al mismo tiempo que el formato hace uso de dicho poder para la difusión de mensajes reivindicativos.

\section{REFERENCIAS}

Baxter, R.L.; De-Reimer, C.; Landina, A., Leslie, L. \& Singletary, M.W. (1985). A Content Analysis of Music Videos. Journal of Broadcasting \& Electronic Media, 29(3), 333-340.

Bryant, J. \& Zillmann, D. (1996). El entretenimiento como efecto de los media, en Bryant, J. \& Zillmann, D. (Coords.). Los efectos de los medios de comunicación: Investigaciones y teorías. Barcelona: Paidós Ibérica.

Colás, P. \& Villaciervos, P. (2007). La interiorización de los estereotipos de género en jóvenes y adolescentes. Revista de Investigación Educativa, 25, 1, 35-58. Recuperado de: http://goo.gl/nQckRF

Cuesta, M. (2007). Videoclisión: Relaciones entre teleseries y videoclips en seis capitulos. Santiago: Xunta de Galicia.

García-Ruiz, R.; Aguaded-Gómez, J.I. \& Rodríguez-Vázquez, A.I. (2014-2015). Propuesta de alfabetización mediática ante los estereotipos de género en los medios de comunicación. Resultados y valoración de 'Rostros de Mujer'. Prisma Social, 13, 576-609. Recuperado de: http://goo.gl/aD9BmT

Gibbs, G. (2012). El análisis de datos cualitativos en investigación Cualitativa. Madrid: Morata.

Gill, R. \& Scharff, C. (2011). Introduction, en Gill, R. \& Scharff, C. (Eds.). New Femininities: Postfeminism, Neoliberalism and Subjectivity. (pp.1-17). Basingstoke: Palgrave McMillan.

Inness, S. A. (2004). Boxing gloves and bustiers: New images of tough women, en Innes, S.A. (Ed.). Action Chicks. New Images of Tough Women in Popular Culture. (pp. 2-17). Nueva York: Palgrave, Macmillan.

Markman, R. (1998). La Cultura global del "Sputnik": Un modelo de valores para la juventud. Trabajo de investigación doctoral. Barcelona: Universidad Autónoma de Barcelona. 
Márquez, I.V. (2014). La imagen de la mujer en los videoclips de Hip-Hop. Versión. Estudios de Comunicación y Política, 33, 181-189.

Martínez-Noriega, D.A. (2014). Música, imagen y sexualidad: El reggaetón y las asimetrías de género. El Cotidiano, 186, 63-67.

McMillan, J.H. \& Schumacher, S. (2005). Investigación educativa. Una introducción conceptual. Madrid: Pearson.

Noir, R.A. (2010). Sobre el Movimiento Lésbico-Gay Homosexual-Bisexual Transgénero. Revista electrónica de Psicología Política, 8, 22, 128-140. Recuperado de: http://goo.gl/z6rzGl.

Penalva, C. (2002) "El tratamiento de la violencia en los medios de comunicación". Alternativas. Cuadernos de Trabajo Social, 10, 395-412.

Railton, D. \& Watson, P. (2011). Music Video and the Politics of Representation. Edinburgh: University of Edinburgh Press.

Roncero-Palomar, R. (2008). Antivídeo: Estética e intermedialidad. Tesis doctoral. Madrid: Universidad Rey Juan Carlos.

Selva, D. (2012). Nuevos fenómenos en el entorno on line. La difusión del videoclip a través de internet. Telos, Cuadernos de Comunicación e Innovación.

Seidman, S.A. (1992). An Investigation of Sex-Role Stereotyping in Music Videos. Journal of Broadcasting and Electronic Media, 36(2), 209-216.

Sherman, B. \& Dominick, J.R. (1986). Violence and Sex in Music Videos: TV and Rock'n'Roll. Journal of Communication, 36 (1), 79-93.

Sommers-Flanagan, R.; Sommers-Flanagan, J. \& Davis, B. (1993). What's Happening on Music Television? A Gender Role Content Analysis. Sex Roles, 28 (11/12), 745583.

Tapper, J.; Thorson, E. \& Black, D. (1994). Variations in Music Videos as a Function of Their Musical Genre. Journal Broadcasting E Electronic Media, 38 (1), 103-113.

Taylor, S.J. \& Bogdan, R. (1987). Introducción a los métodos cualitativos de investigación. La búsqueda de significados. Barcelona: Paidós.

Tortajada, I. \& Araüna, N. (2014). "Mujeres, violencia y posfeminismo en los vídeos de Madonna". Área Abierta, 14(3), 23-41. doi: http://dx.doi.org/10.5209/rev_ARAB.2014.v14.n3.45851 
Vernallis, C. (1998). The Aesthetics of Music Video: An Analysis of Madonna's Cherish. Popular Music, 17(2), 153-185

Vincent, R.C. (1989). Clio's Consciousness Raised? Portrayal of Woman in Rock Videos, Re-Examined. Journalism Quarterly, 66, 155-160.

\section{AUTORES \\ Jennifer Rodríguez-López}

Es doctora en Educación y Comunicación Audiovisual, Máster en Patrimonio Histórico y Natural y licenciada en Humanidades por la Universidad de Huelva (Andalucía, España). Su tesis doctoral trata sobre los vídeos musicales producidos por Andy Warhol, creando una plantilla metodológica para este formato. Ha trabajado como Técnico en Patrimonio Universitario en dicha institución onubense y ha participado en un proyecto financiado por la Junta de Andalucía sobre alfabetización mediática. Es miembro del Grupo de Investigación Ágora y es Miembro del Comité de Revisores Científicos Internacionales de la Revista Científica de Comunicación y Educación «Comunicar». Ha publicado varios artículos sobre el videoclip en relación a diversos ámbitos como la alfabetización mediática, los videojuegos o los estereotipos de género, así como trabajos científicos sobre la figura del artista Andy Warhol.

https://www.researchgate.net/profile/Jennifer_Rodriguez-Lopez

\section{Ana María Sedeño-Valdellós}

Es doctora en Comunicación Audiovisual y Profesora en la Universidad de MálagaAndalucía Tech (España). Sus líneas de investigación principales son las nuevas prácticas audiovisuales en el panorama audiovisual y los formatos audiovisuales publicitarios. Recientemente ha publicado un libro junto a Pedro Mature y María Jesús Ruíz titulado: Panorama del cine iberoamericano en un contexto global. Historias comunes, propuestas, futuro. Madrid: Dykinson, SL. Así como un capítulo de libro titulado "Cine y postcine: transformaciones del audiovisual en la contemporaneidad" en Multiculturalidad, imagen y nuevas tecnologias. Fragua, 2014. También el artículo "El videoclip musical postelevisivo: Ámbitos de experimentación en el audiovisual digital" en Revista Opción. núm. 1.

https://www.researchgate.net/profile/Ana_Sedeno 